\title{
A HIGH-THROUGHPUT, LOW-COST METHOD FOR ANALYSIS OF CARBONATE SAMPLES FOR ${ }^{14} \mathrm{C}$
}

\author{
Mark L Roberts ${ }^{1}$ Steven R Beaupré • Joshua R Burton \\ Woods Hole Oceanographic Institution, Woods Hole, Massachusetts 02543, USA.
}

\begin{abstract}
The National Ocean Sciences Accelerator Mass Spectrometry (NOSAMS) facility at the Woods Hole Oceanographic Institution has developed an automated system for high-throughput, low-cost analysis of radiocarbon in carbonate samples (e.g. corals, carbonaceous sediments, speleothems, etc.). The method bypasses graphitization and pretreatment, and reduces costs to about $1 / 5$ th the price of a graphite-based ${ }^{14} \mathrm{C}$ carbonate analysis, with a throughput of 60 unknowns per day and an analytical precision of better than $2 \%$. Additionally, a simple mixing experiment indicated that extensive cleaning of carbonate samples to remove organic material is not necessary.
\end{abstract}

\section{INTRODUCTION}

Marine carbonates provide a robust record of the chemical composition and physical environment of the seas in which they were formed. For example, observations from banded coral cores (and from forams from sediment cores, etc.) have revealed variations in radiocarbon content indicative of changes in ocean circulation, climate, and anthropogenic perturbations to the global carbon cycle (Druffel 1997). In most cases, the interpretation of individual cores implicitly assumes an Eulerian framework of observation, in which time-dependent changes in the isotopic composition of local seas and changes in the flow of isotopically distinct water masses become archived by a stationary coral. While multiple cores could, in principle, improve constraints on the 4-dimensional nature of the ocean, the cost and effort required for large quantities of ${ }^{14} \mathrm{C}$ accelerator mass spectrometry (AMS) measurements have precluded surveys of marine carbonates with high spatiotemporal resolution.

Traditionally, carbonate samples are converted to $\mathrm{CO}_{2}$ by acidification, then reduced to graphite, and subsequently pressed into a target cartridge for analysis using a cesium sputter ion source. Graphitization and target pressing is time consuming and can be costly because of the labor involved. Therefore, we have developed an automated sample acidification and sample delivery system coupled to the recently developed NOSAMS gas ion source for analysis of the ${ }^{14} \mathrm{C}$ content of carbonate samples. This method bypasses the graphitization and target pressing steps essential to graphite base sputter ion-source AMS, allowing for rapid, low-cost reconnaissance-type measurements to be made.

Additionally, carbonate samples are often pretreated to remove organic carbon impurities, which can reach up to $\leq 4 \% \mathrm{w} / \mathrm{w}$ in mound-forming corals (Wainright 1962; Bak and Laane 1987; Ingalls et al. 2003). Pretreatments require additional time, resources, and may even compromise the fidelity of $\delta^{13} \mathrm{C}$ signatures (Wierzbowski 2007), although their influence on ${ }^{14} \mathrm{C}$ measurements has not yet been evaluated. Therefore, we assessed the need for pretreatment in reconnaissance ${ }^{14} \mathrm{C}$ measurements by evaluating the selectivity of carbonate acidification in the presence of organic contamination.

${ }^{1}$ Corresponding author. Email: mroberts@whoi.edu.

(c) 2013 by the Arizona Board of Regents on behalf of the University of Arizona Proceedings of the 21 st International Radiocarbon Conference edited by A J T Jull \& C Hatté RADIOCARBON, Vol 55, Nr 2-3, 2013, p 585-592 


\section{$M L$ Roberts et al.}

\section{METHOD}

\section{Automated Carbonate System}

The method starts with weighing carbonate samples into 7-mL septa-sealed glass vials (Labco, code: $768 \mathrm{~W}$ ). Typical sample mass is $30 \mathrm{mg}$ of carbonate ( $3.6 \mathrm{mg}$ of carbon), but samples as small as $10 \mathrm{mg}$ of carbonate (1.2 $\mathrm{mg}$ of carbon) have been run. Weighed samples are placed in racks for processing. In the racks, ordered around the unknowns, are also vials containing secondary standards (e.g. IAEA C-2 reference material), vials containing ${ }^{14} \mathrm{C}$-"dead" material (e.g. IAEA C-1 reference material), and vials containing a reference gas used for normalization purposes. Racks of vials are processed by a highly modified Gilson ${ }^{\circledR}$ GX-271 Liquid Handler (Gilson Inc.). A photograph of the Gilson device is shown in Figure 1.

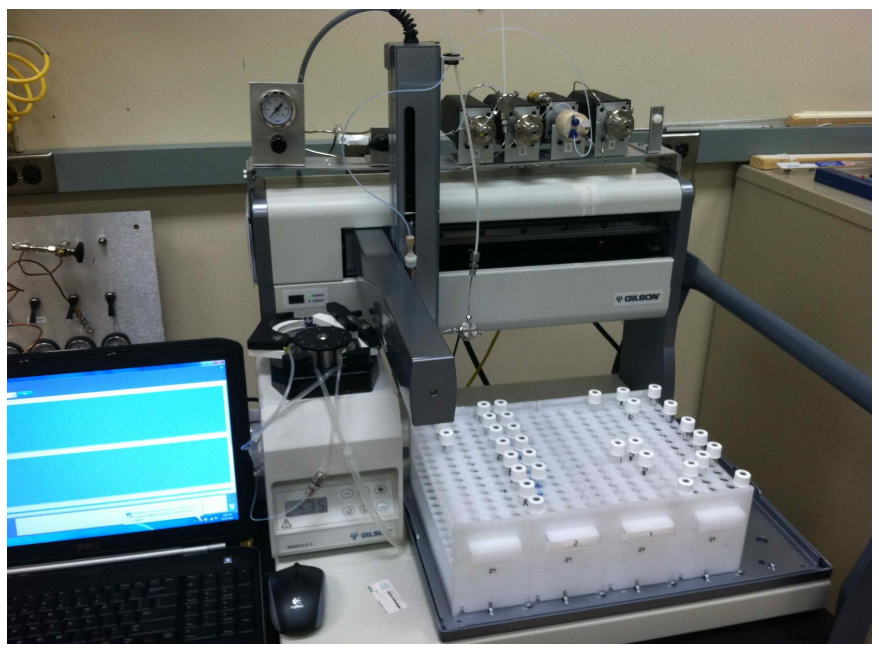

Figure 1 The modified Gilson Liquid Handler. Racks of vials are seen at the lower right. A peristaltic pump is on the left. The 3-axis arm that holds the double-needle assembly is at the center. On top of the Gilson is a row of 4 Valco valves to switch in/out vacuum, acid, water, argon, etc.

Carbonate samples and standards are processed by evacuating the vials and then injecting phosphoric acid. This is done using a double-concentric needle apparatus as is shown schematically in Figure 2 (and similar to the one described in McIlvin and Casciotti 2010). Vials are evacuated to less than $10 \mathrm{mTorr}$ through the outer needle using a dry high-vacuum system with a turbo and diaphragm pump. Then, $1 \mathrm{~mL}$ of $\mathrm{H}_{3} \mathrm{PO}_{4}$ acid $\left(\mathrm{H}_{3} \mathrm{PO}_{4}, 85.0 \mathrm{w} / \mathrm{w} \%\right.$, Fisher Chemical, catalog number A242-4) is injected through the center needle. A Gilson Minipuls 3 peristaltic pump controls the acid injection rate. With experience, we have found that vacuum integrity is better maintained if the needles are occasionally coated with a thin layer of vacuum grease. This is automatically accomplished by cycling the needle assembly through a "dummy" vial that has a thick layer of Apezion ${ }^{\circledR}$ "M" vacuum grease on either side of the septa. Between vials, the double-needle apparatus is moved to a "waste position" and the inner needle is purged with argon (Commercial Grade [grade 4.6], Corp Brothers, Inc.). Vacuum pumping, acid injection, line purging, etc,. is all accomplished using a series of programmable Valco valves (VICI ${ }^{\circledR}$ Valco Instruments, Inc.). Control of the valves and movement of the double-needle assembly between vials is done using a custom program written using Gilson's TRILUTION ${ }^{\circledR}$ software. Sample preparation is sequential (i.e. 1 vial is evacuated and acid is injected before moving to the next vial). 
High-Throughput, Low-Cost Method for Carbonate Samples
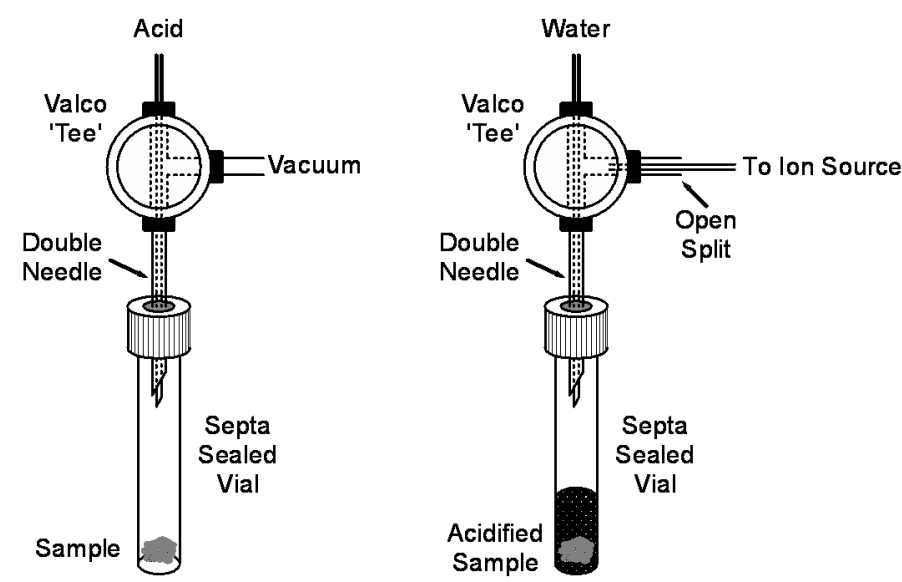

Figure 2 Double-needle configuration (not to scale) used for sample acidification and sample delivery. For acidification, the sample vials are first evacuated through the outer needle to $<10 \mathrm{mTorr}$, then $1 \mathrm{~mL}$ of $85 \%$ phosphoric acid is added through the inner needle. For $\mathrm{CO}_{2}$ gas delivery to the ion source, water is pumped into the vial through the inner needle, resulting in the $\mathrm{CO}_{2}$ being positively displaced through an open split to the source. The entire double-needle assembly is mounted on the arm of the Gilson GX-271 and moves between rack vial positions.

Roughly every 6th vial contains a $\mathrm{CO}_{2}$ reference gas (Instrument Grade [grade 4.0], Airgas East Inc.) with a fraction modern (Fm) value of $1.0398 \pm 0.0006$ (as determined using graphite-based AMS measurements). These "reference gas" vials are used as normalizing standards in the data reduction process. The Gilson evacuates then backfills empty vials with the reference gas after it has completed preparing the carbonate samples and standards.

After evacuation and acid injection, vials containing samples and standards are incubated for several hours (typically overnight) in a $60^{\circ} \mathrm{C}$ water bath. This allows the acidification process to proceed to completion. For a typical 30-mg carbonate sample, between 6 and $7 \mathrm{~mL}$ of $\mathrm{CO}_{2}$ is evolved. With the $1 \mathrm{~mL}$ of $\mathrm{H}_{3} \mathrm{PO}_{4}$, this brings the 7-mL vials to slightly positive pressure. We are in the process of building custom racks that are internally heated to eliminate any need for the off-line water bath.

Delivery of $\mathrm{CO}_{2}$ gas is as shown in Figure 2. Acidified ( $\mathrm{pH}<4$ ), sparged (using $\sim 200 \mathrm{~mL} / \mathrm{min}$ of $\mathrm{He}$ ), triple-distilled water is introduced into the vials through the inner needle using the controllable Gilson peristaltic pump. The typical flow rate is 500 or $600 \mu \mathrm{L} / \mathrm{min}$. As the water flows in, $\mathrm{CO}_{2}$ is positively displaced out of the vial through the larger outer needle for delivery to the gas ion source using a glass capillary. An open split that is integral to the double-needle assembly is used to maintain a constant pressure at the inlet of the capillary. In operation, care must be taken so the sample vial does not overfill and cause water to reach the outer needle and enter the open split and ion source. Argon is used to back-flush both the sample line and open split between the samples. Movement of the double-needle apparatus from vial to vial is controlled by communication of the AMS data acquisition system with the Gilson software.

$\mathrm{CO}_{2}$ is delivered to the gas ion source using a $100-\mu \mathrm{m}$-inner-diameter deactivated fused-silica capillary (SGE Analytical Science, $\mathrm{P} / \mathrm{N}$ 0624455) that is $\sim 1.6 \mathrm{~m}$ long. This corresponds to a $\mathrm{CO}_{2}$ flow rate of $370 \mu \mathrm{L} / \mathrm{min}$. By varying the length of the capillary, different gas flow rates can be obtained. The operating principle of the gas ion source is outlined elsewhere (Roberts et al. 2013). Data is collected using a customized data acquisition system described in von Reden et al. (2008). 


\section{$M L$ Roberts et al.}

\section{Pretreatment Experiment}

In order to determine the selectivity of carbonate acidification, aliquots of a modern carbonate (Druffel Coral Standard, Fm $=0.9456 \pm 0.0019$, as determined by numerous graphite-based AMS measurements using NOSAMS's $500 \mathrm{kV}$ AMS system) were mixed in increasing proportions (0 to $56 \mathrm{w} / \mathrm{w} \%$, Table 1) with ${ }^{14} \mathrm{C}$-depleted organic matter in the form of acetanilide $\left(\mathrm{C}_{6} \mathrm{H}_{5} \mathrm{NHCOCH}_{3}\right.$, JT Baker) and aspartic acid $\left(\mathrm{C}_{4} \mathrm{H}_{7} \mathrm{NO}_{4}\right.$, Sigma Life Sciences). Aspartic acid was specifically chosen because it is a high-reactivity amino acid. For comparison, aliquots of the IAEA C-1 carbonate $(\mathrm{Fm}=$ 0.0002 , Rozanski et al. 1992) were intentionally mixed in increasing proportions ( 0 to $53 \mathrm{w} / \mathrm{w} \%$, Table 1) with a modern organic carbon contaminant in the form of humic acid (FIRI G/J, Fm = $1.107 \pm 0.0004$, Scott 2006). In our study, the proportion of organic contamination exceeded that expected from natural samples by over an order of magnitude. The ${ }^{14} \mathrm{C}$ contents of the mixtures were then quantified using the methods described above.

Table 1 Carbonate mass and mass of organic contaminate.

\begin{tabular}{|c|c|c|c|c|c|}
\hline \multirow[b]{2}{*}{ Sample } & \multicolumn{2}{|c|}{ Coral standard } & \multicolumn{2}{|c|}{ Acetanilide } & \multirow{2}{*}{$\begin{array}{l}\text { Organic carbon/ } \\
\text { total carbon } \\
\mathrm{w} / \mathrm{w} \%\end{array}$} \\
\hline & $\mathrm{mg}$ & $\mathrm{mg} \mathrm{C}^{\mathrm{a}}$ & $\mathrm{mg}$ & $\mathrm{mg} \mathrm{C}^{\mathrm{b}}$ & \\
\hline 1 & 31.15 & 3.74 & & 0.00 & $0 \%$ \\
\hline 2 & 31.15 & 3.74 & & 0.00 & $0 \%$ \\
\hline 3 & 29.99 & 3.60 & 1.17 & 0.83 & $19 \%$ \\
\hline 4 & 29.86 & 3.58 & 1.73 & 1.23 & $26 \%$ \\
\hline 5 & 30.31 & 3.64 & 2.49 & 1.77 & $33 \%$ \\
\hline 6 & 29.74 & 3.57 & 4.92 & 3.50 & $49 \%$ \\
\hline \multirow[t]{2}{*}{7} & 30.85 & 3.70 & 6.54 & 4.65 & $56 \%$ \\
\hline & \multicolumn{2}{|c|}{ Coral standard } & \multicolumn{2}{|c|}{ Aspartic acid } & $\begin{array}{l}\text { Organic carbon/ } \\
\text { total carbon }\end{array}$ \\
\hline Sample & $\mathrm{mg}$ & $\mathrm{mg} \mathrm{C}^{\mathrm{a}}$ & $\mathrm{mg}$ & $\mathrm{mg} \mathrm{C}^{\mathrm{c}}$ & $\mathrm{w} / \mathrm{w} \%$ \\
\hline 8 & 38.30 & 4.60 & & 0.00 & $0 \%$ \\
\hline 9 & 30.60 & 3.67 & 2.10 & 0.76 & $17 \%$ \\
\hline 10 & 30.34 & 3.64 & 3.49 & 1.26 & $26 \%$ \\
\hline 11 & 29.94 & 3.59 & 4.99 & 1.80 & $33 \%$ \\
\hline \multirow[t]{2}{*}{12} & 30.86 & 3.70 & 9.69 & 3.50 & $49 \%$ \\
\hline & \multicolumn{2}{|c|}{ IAEA C-1 } & \multicolumn{2}{|c|}{ FIRI G } & $\begin{array}{l}\text { Organic carbon/ } \\
\text { total carbon }\end{array}$ \\
\hline Sample & $\mathrm{mg}$ & $\mathrm{mg} \mathrm{C}^{\mathrm{a}}$ & $\mathrm{mg}$ & $\mathrm{mg} \mathrm{C}^{\mathrm{d}}$ & $\mathrm{w} / \mathrm{w} \%$ \\
\hline 13 & 31.85 & 3.82 & & 0.00 & $0 \%$ \\
\hline 14 & 33.03 & 3.96 & & 0.00 & $0 \%$ \\
\hline 15 & 31.49 & 3.78 & & 0.00 & $0 \%$ \\
\hline 16 & 33.05 & 3.97 & & 0.00 & $0 \%$ \\
\hline 17 & 30.00 & 3.60 & 1.43 & 0.69 & $16 \%$ \\
\hline 18 & 30.94 & 3.71 & 2.44 & 1.17 & $24 \%$ \\
\hline 19 & 29.50 & 3.54 & 3.77 & 1.81 & $34 \%$ \\
\hline 20 & 31.15 & 3.74 & 7.59 & 3.64 & $49 \%$ \\
\hline 21 & 30.10 & 3.61 & 8.40 & 4.03 & $53 \%$ \\
\hline
\end{tabular}

${ }^{\mathrm{a}} 12 \% \mathrm{C}$ by weight; ${ }^{\mathrm{b}} 71 \% \mathrm{C}$ by weight; ${ }^{\mathrm{c}} 36 \% \mathrm{C}$ by weight; $\mathrm{d} 48 \% \mathrm{C}$ by weight. 


\section{RESULTS}

A typical sequence consists of measurements of a suite of vials containing "reference gas," "deadgas" (IAEA C-1), secondary standards (IAEA C-2), and $\mathrm{CO}_{2}$ derived from the unknowns. An example of a 10-vial run sequence is shown in Figure 3. Typical analysis time on each individual sample is 5 to $6 \mathrm{~min}$. In this run, measured blank values of $\mathrm{Fm} \approx 0.008$ were obtained (corresponding to a Libby age of about $40 \mathrm{kyr}$ before present). Demonstrating the long-term fidelity of the system, Figure 4 shows measurements of the IAEA C-2 standard (treated as an unknown) over the 12 months preceding July 2012. The average value of the results was $F m=0.4130 \pm 0.0036(1 \sigma)$. The accepted value of IAEA C-2 is Fm $=0.4114 \pm 0.0003$ (Rozanski et al. 1992).
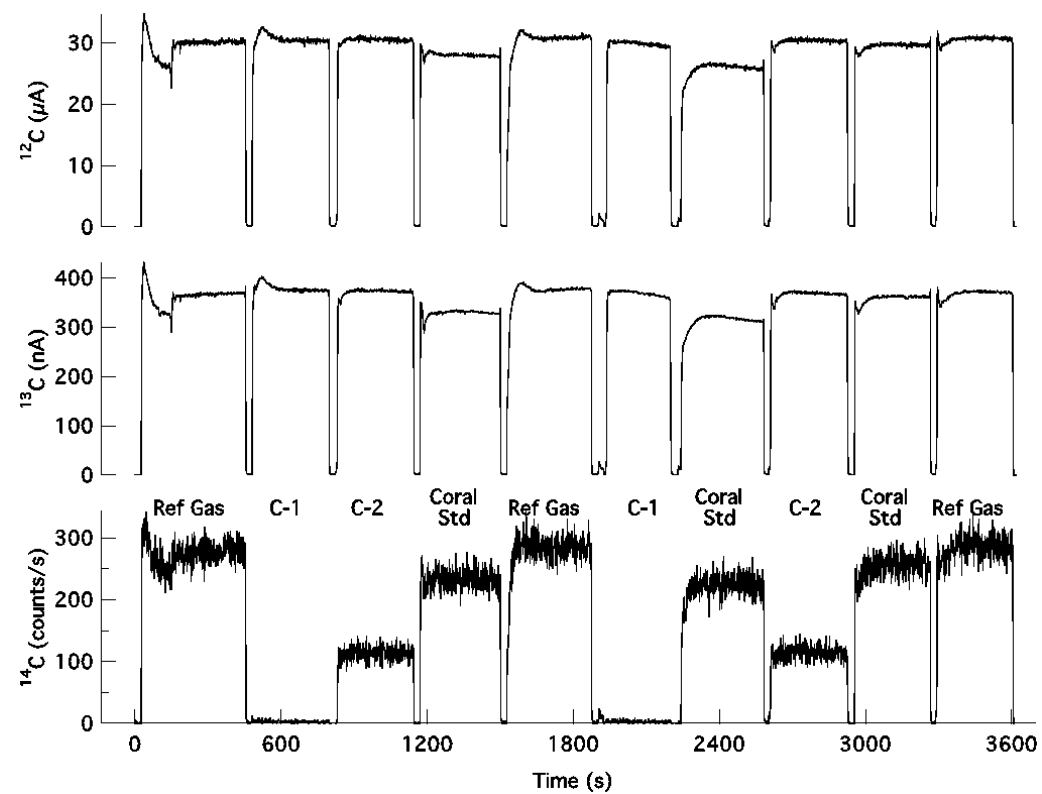

Figure 3 Run sequence of reference gas $(\mathrm{Fm}=1.0398)$, IAEA C-1 and C-2 standards $(\mathrm{Fm}=$ 0.0002 and 0.4114 , respectively), and an internal coral standard $(\mathrm{Fm}=0.942) .{ }^{12} \mathrm{C}$ and ${ }^{13} \mathrm{C}$ ion currents are as measured on the high-energy off-axis Faraday cups.

As previously reported, overall total efficiency of the system is quite low at $0.2 \%$ (Roberts et al. 2013). Nonetheless, as can be seen in Figure 3, high-energy ${ }^{12} \mathrm{C}$ and ${ }^{13} \mathrm{C}$ ion currents and ${ }^{14} \mathrm{C}$ count rates when using the gas ion source compare favorably to those obtained when using a graphite source. For a modern sample, we typically accumulate greater than $75,000{ }^{14} \mathrm{C}$ events in a 5 -min run. If counting statistics were the limiting factor, analytical precisions of about $\pm 0.004 \%$ (from a modern sample) should be obtained. However, we currently observe drift/instability in the system (as determined by ${ }^{14} \mathrm{C} /{ }^{12} \mathrm{C}$ ratio variations between the reference gas standards) that limits analytical uncertainty to about $2 \%$. We attribute system instability to the large beam emittance of the gas ion source $(\sim 100 \pi \mathrm{mm}$ mrad, Roberts et al. 2013), which causes the beam to not be transmitted cleanly through the stripper canal of the accelerator. Observed $\mathrm{C}^{-}$to $\mathrm{C}^{+}$transmission through the accelerator for the gas ion source is $\sim 29 \%$ versus an observed transmission of $\sim 40 \%$ when using the sputter ion source. This poor transmission makes the system sensitive to small changes within the gas ion source that occur as the source warms up or as samples with slightly different gas mixtures are introduced. 


\section{$M L$ Roberts et al.}

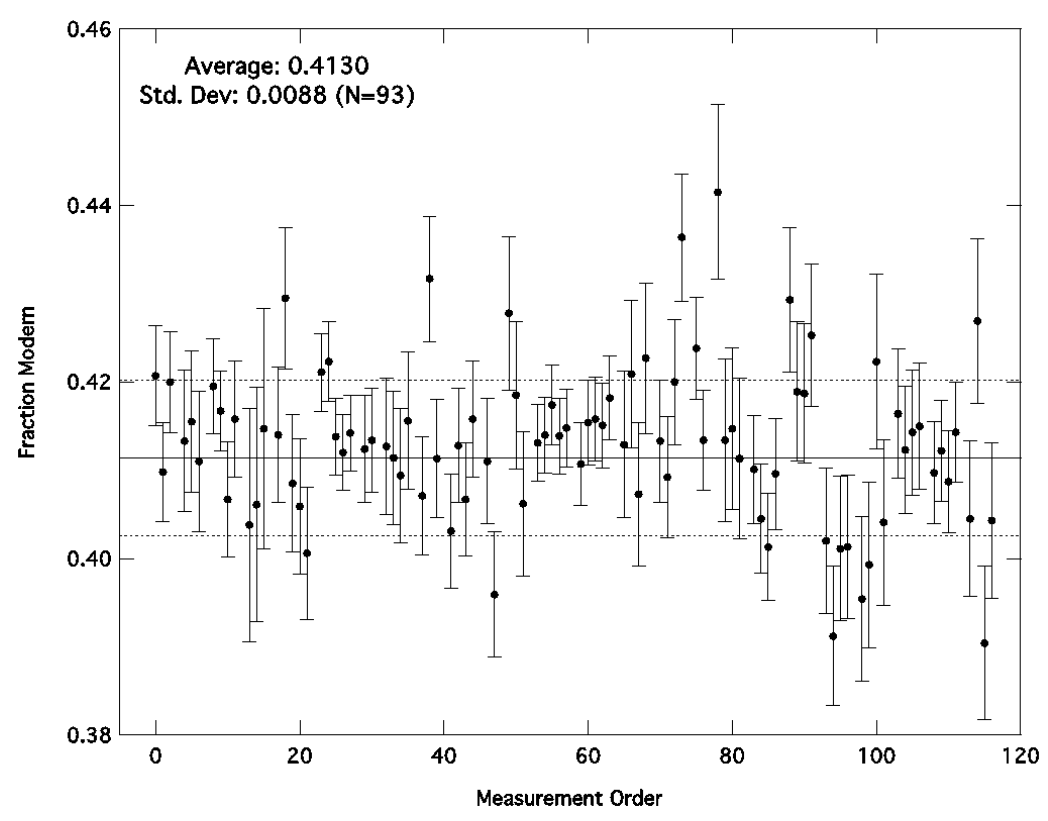

Figure 4 Measurements of the IAEA C-2 standard over the 12 months preceding July 2012

Figure 5 shows measured Fm results from the modern carbonate and ${ }^{14} \mathrm{C}$-depleted organic acetanilide and aspartic acid mixtures. The average of the 9 data points (in which ${ }^{14} \mathrm{C}$-depleted contaminant was added) is $\mathrm{Fm}=0.9401 \pm 0.0092(1 \sigma)$. This is statistically equivalent to the value of $\mathrm{Fm}=$ $0.9456 \pm 0.0019$ obtained from graphite-based AMS measurements. Figure 6 shows results from the ${ }^{14} \mathrm{C}$-depleted IAEA C-1 standard and above-modern humic acid mixtures. The average of the 5 data points (in which modern contaminant was added) is $\mathrm{Fm}=-0.0003 \pm 0.0013(1 \sigma)$. This is statistically equivalent to the accepted value of $\mathrm{Fm}=0.0002$. As can be seen from both Figures 5 and 6 , there is no discernable trend in Fm with increasing abundances of isotopically disparate contamination. This indicates that the acidification method selectively converts carbonate to $\mathrm{CO}_{2}$ within uncertainty of the measured values. Therefore, sample pretreatment to remove extraneous organic matter is not necessary for reconnaissance ${ }^{14} \mathrm{C}$ measurements of carbonates. However, the effect and detectability of organic contamination on ${ }^{14} \mathrm{C}$ analyses of carbonates has not yet been evaluated by the higherprecision methods of AMS. The need for pretreatment under these analytical constraints should be verified. Likewise, the effect of secondary carbonate contamination (Bard et al. 1990; Burr et al. 1992; Yokoyama et al. 2000) on reconnaissance ${ }^{14} \mathrm{C}$ measurements has not yet been evaluated.

\section{SUMMARY}

We have developed an automated system for high-throughput, low-cost analysis of ${ }^{14} \mathrm{C}$ in carbonate samples (e.g. corals, carbonaceous sediments, speleothems, etc.). Our tests indicate that, to a very high degree, extensive pretreatments and graphitization can be bypassed in reconnaissance ${ }^{14} \mathrm{C}$ measurements. With a typical analysis time per sample of 5 to $6 \mathrm{~min}$, we can process approximately 60 unknowns ( 90 vials total) to an analytical precision better than $2 \%$, in an 8 -hr day. Collectively, for the same effort/cost, 5 times as many measurements can be made using this method as opposed to a graphite-based ${ }^{14} \mathrm{C}$ carbonate analysis method. Therefore, this system is suitable for reconnaissance ${ }^{14} \mathrm{C}$ dating where large numbers of samples need to be analyzed quickly at low-cost, and for the selection of samples for further high-precision analyses using graphite-based techniques. 
High-Throughput, Low-Cost Method for Carbonate Samples

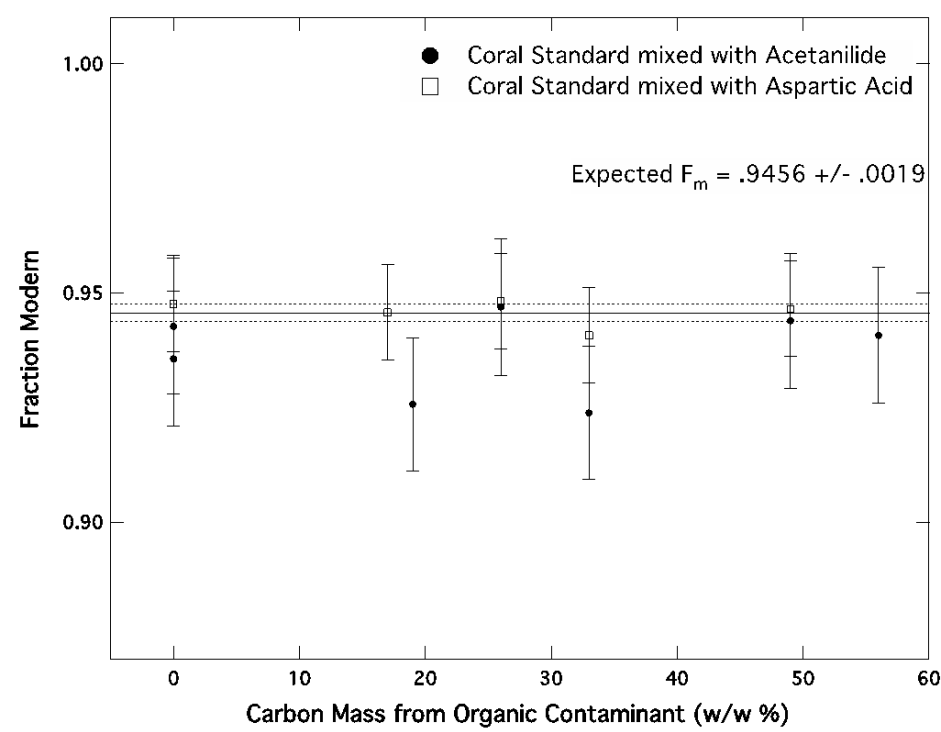

Figure $5 \mathrm{Fm}$ results from the modern carbonate standard mixed in increasing proportions with a ${ }^{14} \mathrm{C}$-depleted organic matter in the form of acetanilide and aspartic acid. As can be seen, there is no discernable trend in Fm with increasing abundances of isotopically disparate contamination.

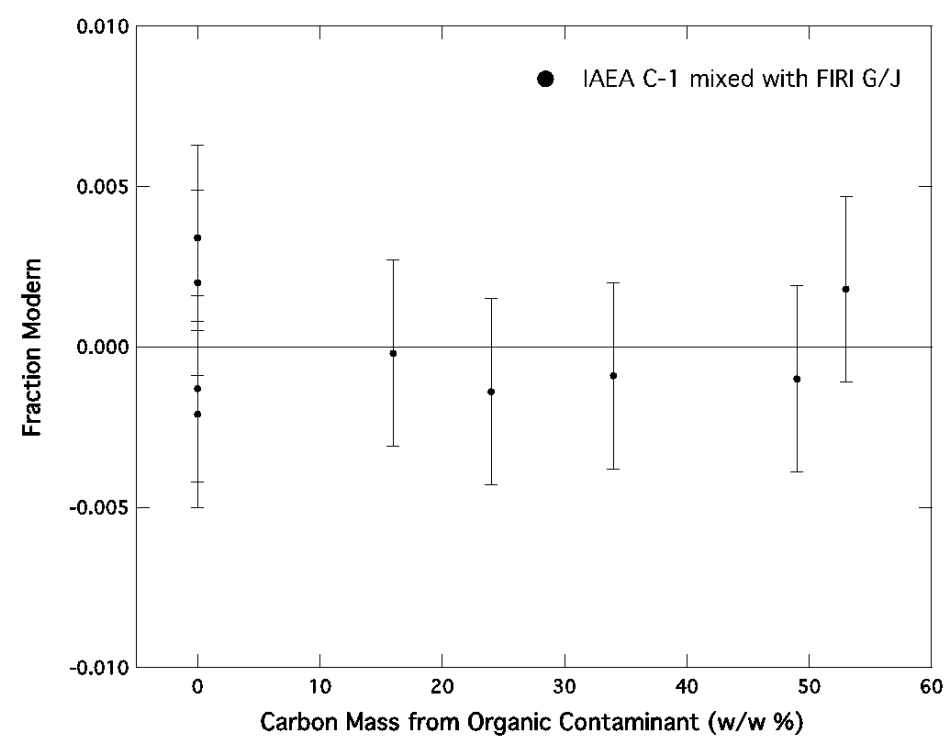

Figure $6 \mathrm{Fm}$ results from the ${ }^{14} \mathrm{C}$-depleted IAEA C-1 standard mixed in increasing proportions with a modern organic carbon contaminate in the form of humic acid (FIRI G/J). As can be seen, there is no discernable trend in Fm with increasing abundances of isotopically disparate contamination. Negative Fm values are nonsensical and are due to blank subtraction (i.e. in some cases, the measured ${ }^{14} \mathrm{C} /{ }^{12} \mathrm{C}$ ratios of the mixture was slightly lower than the average measured ${ }^{14} \mathrm{C} /{ }^{12} \mathrm{C}$ ratios of the cleaned/uncontaminated C-1 blank). 


\section{$M L$ Roberts et al.}

\section{ACKNOWLEDGMENTS}

This work is supported by a Cooperative Agreement (OCE- 2310753487) with the US National Science Foundation.

\section{REFERENCES}

Bak RPM, Laane RWPM. 1987. Annual black bands in skeletons of reef corals (Scleractinia). Marine Ecology Progress Series 38:169-75.

Bard E, Hamelin B, Fairbanks RG, Zindler A. 1990. Calibration of the ${ }^{14} \mathrm{C}$ timescale over the past 30,000 years using mass spectrometric U-Th ages from Barbados corals. Nature 345(6274):405-10.

Burr GS, Edwards RL, Donahue DJ, Druffel ERM, Taylor FW. 1992. Mass spectrometric ${ }^{14} \mathrm{C}$ and U-Th measurements in coral. Radiocarbon 34(3):611-8.

Druffel ERM. 1997. Geochemistry of corals: proxies of past ocean chemistry, ocean circulation, and climate. Proceedings of the National Academy of Science of the USA 94(16):8354-61.

Ingalls AE, Lee C, Druffel ERM. 2003. Preservation of organic matter in mound-forming coral skeletons. Geochimica et Cosmochimica Acta 67(15):2877-41.

McIlvin MR, Casciotti KL. 2010. Fully automated system for stable isotopic analyses of dissolved nitrous oxide at natural abundance levels. Limnology and Oceanography: Methods 8:54-66.

Roberts ML, von Reden KF, Burton JR, McIntyre CP, Beaupré SR. 2013. A gas-accepting ion source for accelerator mass spectrometry: progress and applica- tions. Nuclear Instruments and Methods in Physics Research B 294:296-9.

Rozanski K, Stichler W, Gonfiantini R, Scott EM, Beukens RP, Kromer B, van der Plicht J. 1992. The IAEA ${ }^{14} \mathrm{C}$ Intercomparison Exercise 1990. Radiocarbon 34(3):506-19.

Scott EM. 2006. Section 10: summary and conclusions. Radiocarbon 45(2):285-90.

von Reden KF, Roberts ML, Jenkins WJ, Rosenheim BE, McNichol AP, Schneider RJ. 2008. Software development for continuous-gas-flow AMS. Nuclear Instruments and Methods in Physics Research B 266(10): 2233-7.

Wainright SA. 1962. An anthozoan chitin. Experientia 18:18-9.

Wierzbowski H. 2007. Effects of pre-treatments and organic matter on oxygen and carbon isotope analyses of skeletal and inorganic calcium carbonate. International Journal of Mass Spectrometry 268(1):16-29.

Yokoyama Y, Esat TM, Lambeck K, Fifield LK. 2000. Last ice age millennial scale climate changes recorded in Huon Peninsula corals. Radiocarbon 42(3):383401. 